\title{
Proposal of possible pathway of fluorene biodegrada- tion by Citrobacter sp. FL5
}

\author{
Xuejiao Zhu, Minsheng Huang, Qiuzhuo Zhang and Varenyam Achal* \\ School of Ecological and Environmental Sciences, East China Normal University, Shanghai, People’s Republic of China
}

\begin{abstract}
The biodegradation ability of Citrobacter sp. FL5 on fluorene was investigated in the present study. The bacterial isolate was identified based on biochemical test, physiological and 16S rDNA sequence analysis. Fluorene biodegradation was studied in the liquid media at the initial concentration of $50 \mathrm{mg} \mathrm{L}^{-1}$ fluorene at different $\mathrm{pH}$ values $(6,7$, 8 and 9) and temperatures (25, 30, 37 and $45^{\circ} \mathrm{C}$ ). Citrobacter sp. FL5 showed maximum performance of fluorene degradation ability at $\mathrm{pH} 7$ and $30^{\circ} \mathrm{C}$ where it degrades $98 \%$ fluorene in liquid media. Furthermore, the isolate degrades $97.5 \%$ and $96 \%$ of 100 and $150 \mathrm{mg} \mathrm{L}^{-1}$ fluorene respectively at $168 \mathrm{hrs}$. The possible metabolic pathway for fluorene biodegradation by Citrobacter sp. FL5 was deduced by identification of metabolites through Gas Chromatography Mass Spectrometry (GC-MS) technique. 5 types of metabolites that were detected and identified were dibenzofuran, 9-fluorenylmethanol, methyl benzilate, piperonylic acid and catechol. This study was the first to report and describe the ability of Citrobacter sp. in detail for degradation of higher fluorene concentrations at various $\mathrm{pH}$ and temperatures ranges.
\end{abstract}

Keywords: Citrobacter sp., fluorene, dibenzofuran, degradation, metabolites, Gas Chromatography Mass Spectrometry (GC-MS)

*Correspondence to: Varenyam Achal, School of Ecological and Environmental Sciences, East China Normal University, Shanghai 200241, China, Email: varenyam@re.ecnu.edu.cn

Received: October 15, 2015; Accepted: March 8, 2016; Published Online: April 8, 2016

Citation: Zhu X, Huang M, Zhang Q, et al. 2016, Proposal of possible pathway of fluorene biodegradation by Citrobacter sp. FL5. Applied Environmental and Biotechnology, vol.1(1): 44-51. http://dx.doi.org/10.26789/AEB.2016.01.009.

\section{Introduction}

$\mathrm{P}$ olycyclic aromatic hydrocarbons (PAHs) are a wide group of xenobiotic pollutants, consisting of benzene rings fused into different arrangements, and its hydrophobic physical property makes it hard to degrade in the environment ${ }^{[1,2]}$. Fluorene, a tricyclic PAHs with two fused benzene rings to a cyclopentane ring, is a xenobiotic compound of environmental concern associated with petroleum and oil spills, waste incineration, and industrial effluents ${ }^{[3]}$. Although it has industrial applications in thermo and light sensitizers, luminescence chemistry, spectrophotometric analysis, and molecular chemistry, fluorene and its derivatives are potential toxic and carcinogenic com- pounds that adversely affect living organisms primarily wildlife and human health ${ }^{[4]}$. Moreover, PAHs with three ring fluorene are found abundantly in the ecosystem, and it is of prime importance to discover new bacterial strains for its successful degradation.

Although PAHs can be effectively treated by conventional physicochemical techniques, such treatments are very complex and expensive, in addition to associated high cost and low efficiency. In recent years, biodegradation has been regarded as one of the most promising technique for PAHs remediation. Microorganisms are able to utilize fluorene as a carbon and nutrient source, which leads to a high degree of elimination, although the high quantity of biomass produced may be considered a disadvantage.

Proposal of possible pathway of fluorene biodegradation by Citrobacter sp. FL5. (c) 2016 Xuejiao Zhu, et al. This is an Open Access article distributed under the terms of the Creative Commons Attribution-NonCommercial 4.0 International License (http://creativecommons.org/licenses/by-nc/4.0/), permitting all non-commercial use, distribution, and reproduction in any medium, provided the original work is properly cited. 
Several reports are available on the biodegradation of fluorene by bacteria such as Bacillus, Sphingomonas, Mycobacterium, Pseudomonas, Brevibacterium, Staphylococcus, Arthrobacter and Rhodococcus ${ }^{[5-11]}$. Microbial degradation of fluorene has been investigated for many years; however, there is still considerable interest in the metabolic capacity of fluorene degrading bacteria in various ecosystems. Nevertheless, there is a possibility for various types of bacterial isolates with a capability to show high efficacy in the degradation of fluorene than previously reported.

Rapid industrial growth in the past two decades have lead to soil and water pollution by PAHs, including fluorene in many cities in China. In the present study, Citrobacter sp. was utilized to degrade fluorene in liquid media. The intermediate metabolites in fluorene biodegradation were identified by GC-MS analysis.

\section{Materials and Methods}

\subsection{Sampling Enrichment Culturing and Isolation of Indigenous Bacteria}

The bacterium in this study was isolated from soil samples at an abandoned site in Shanghai, China. The samples were collected into a $100 \mathrm{~mL}$ sterilized bottle containing $50 \mathrm{~mL}$ minimal medium supplemented with $50 \mathrm{mg} \mathrm{L}^{-1}$ fluorene and incubated at $30^{\circ} \mathrm{C}$ in a shaker at $130 \mathrm{rpm}$. After one week of incubation, the supernatant was discarded after centrifugation and re-suspended in similar fresh media. This procedure was repeated twice. Finally, the pellet in the bottle was harvested by centrifuging at $8000 \mathrm{rpm}$ for $10 \mathrm{~min}$ and was used to isolate the bacteria.

The bacterial strains were isolated via serial dilution technique on nutrient agar plates and colonies were transferred to high selection pressure minimal media containing $50 \mathrm{mg} \mathrm{L}^{-1}$ fluorene. Minimal media used consisted of the following components per liter: $3 \mathrm{~g} \mathrm{KH}_{2} \mathrm{PO}_{4}, 8 \mathrm{~g} \mathrm{NaH}_{2} \mathrm{PO}_{4}, 1 \mathrm{~g} \mathrm{NH}_{4} \mathrm{Cl}, 0.5 \mathrm{~g} \mathrm{NaCl}$, $0.2 \mathrm{~g} \mathrm{MgSO}_{4} \cdot 7 \mathrm{H}_{2} \mathrm{O}$, and $2.5 \mathrm{~mL}$ trace element solution. The trace element solution was composed of $23 \mathrm{~g}$ $\mathrm{MnCl}_{2} \times 2 \mathrm{H}_{2} \mathrm{O}, 30 \mathrm{mg} \mathrm{MnCl}_{4} \cdot \mathrm{H}_{2} \mathrm{O}, 20 \mathrm{mg} \mathrm{NiCl} \cdot \cdot 6 \mathrm{H}_{2} \mathrm{O}$,

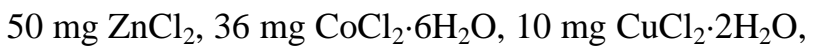
$30 \mathrm{mg} \mathrm{Na} \mathrm{MoO}_{4} \cdot 2 \mathrm{H}_{2} \mathrm{O}$, and $30 \mathrm{mg} \mathrm{H}_{3} \mathrm{BO}_{3}$ in $1 \mathrm{~L}$ distilled water. Media $\mathrm{pH}$ was adjusted to 6.5. During every experiment, fluorene was dissolved in dimethylsulfoxide (DMSO). Minimal media was added after DMSO evaporated. A potential bacterial isolate, designated as FL5 was selected for fluorene degradation studies. The strain was characterized physiologi- cally and biochemically according to the procedures in Bergey's manual $^{[12]}$.

\subsection{Molecular Characterization}

Genomic DNA was isolated from overnight bacterial culture in Luria broth using genomic DNA extraction kit (Sangon Biotech Co. Ltd., Shanghai, China). DNA was dissolved in TE (Tris-EDTA) buffer at $4^{\circ} \mathrm{C}$ overnight. To identify the bacterial isolates, 16S rRNA gene was amplified via polymerase chain reaction (PCR) using genomic DNA as template. The primers used for the amplification and sequencing of the 16S rRNA gene are 5'-AGAGTTTGATCCTGGCTCAG-3' and 5'-AAGGAGGTGATCCAGCCGCA-3' corresponding to the forward and reverse primers of $16 \mathrm{~S}$ rDNA, respectively. The PCR program used was according to Achal and $\operatorname{Pan}^{[13]}$. 16S rRNA amplicon was gel eluted and ligated into pGEM-T vector as per manufacturer's instruction (Promega, USA). The sequences were generated by chain termination method using an Applied Biosystem automated sequencer. The 16S rRNA gene sequence was compared with Ribosomal Database Project-II and with those from GenBank using the BLASTN program. The 16S rRNA gene sequences for FL5 determined in this study were deposited into NCBI's GenBank under the accession number KT890283.

\subsection{Biodegradation Studies of Fluorene}

Biodegradation studies were performed by inoculating bacterial strain FL5 $\left(10^{7} \mathrm{cfu} / \mathrm{mL}\right)$ in a flask containing $50 \mathrm{ml}$ of minimal media supplemented with $50 \mathrm{mg} \mathrm{L}^{-1}$ of fluorene. The flasks were incubated at $30^{\circ} \mathrm{C}$ at 130 rpm for one week (168 hrs). Bacterial growth was determined by measuring the absorbance at $600 \mathrm{~nm}$, and fluorene degradation was quantified by GC-MS at regular time intervals.

The effect of $\mathrm{pH}$ on the degradation of fluorene was studied by growing FL5 at an initial $\mathrm{pH}$ of 6.0, 7.0, 8.0, or 9.0 in minimal media supplemented with $50 \mathrm{mg} \mathrm{L}^{-1}$ of fluorene as the sole carbon source at $30^{\circ} \mathrm{C}$. The effect of temperature on fluorene degradation was also determined by incubating the samples at $25^{\circ} \mathrm{C}, 30^{\circ} \mathrm{C}$, $37^{\circ} \mathrm{C}$ or $45^{\circ} \mathrm{C}$ in a shaker in minimal media supplemented with $50 \mathrm{mg} \mathrm{L}^{-1}$ of fluorene, at an optimal $\mathrm{pH}$ of 7.0.

The effects of fluorene concentration on the growth of strain FL5 and on its fluorene degrading ability was also examined. Isolate FL5 was inoculated in a flask containing $50 \mathrm{ml}$ minimal media supplemented with different concentrations $\left(50,100\right.$, and $\left.150 \mathrm{mg} \mathrm{L}^{-1}\right)$ of 
fluorene. The flasks were incubated at $30^{\circ} \mathrm{C}$ in a shaker at $130 \mathrm{rpm}$ for $168 \mathrm{hrs}$. Bacterial growth was measured using spectrophotometric method at $600 \mathrm{~nm}$ and fluorene degradation efficacy in the culture was measured using GC-MS. Degrading efficiency (D) was calculated using the following equation:

$$
\mathrm{D}(\%)=\left(C_{i}-C_{f} / C_{i}\right) \times 100,
$$

$C_{i}-$ initial concentration of fluorene

$C_{f}$ - final concentration of fluorene

\subsection{Analytical Method}

A gas chromatography mass spectrometer (Agilent 5975C GCMS) with an HP-5MS (30 $\mathrm{m} \times 0.25 \mathrm{~mm}$ I.D. $\times 0.25 \mu \mathrm{m}$ ) and $5 \%$ phenyl methyl silox (Agilent 19091S-433: HP-5MS) fused-silica capillary column, was used for the separation, identification, and quantification of fluorene and its metabolite products. The column temperature program was set at $55^{\circ} \mathrm{C}$ held for $2 \mathrm{~min}, 20^{\circ} \mathrm{C} / \mathrm{min}$ to $280^{\circ} \mathrm{C}$ and $10^{\circ} \mathrm{C} / \mathrm{min}$ to $310^{\circ} \mathrm{C}$ held for $5 \mathrm{~min}$, with a total run time for 24 mins.

The injection volume was set to $1 \mu \mathrm{L}$ in running mode of pulse splitless. The MS was operated in electron impact (EI) ionization mode with an electron energy of $70 \mathrm{eV}$, and the scan to determine the appropriate masses for the selected ion monitoring ranged from 50 to $350 \mathrm{amu}$ (atomic mass unit). The mass spectra of the samples were identified by comparison with standard compounds in the NIST Mass Spectral Search Program (Version 2.0) for the NIST/EPA/NIH Mass Spectral Library.

\section{Results and Discussion}

\subsection{Isolation and Identification of Fluorene De- grading Strain}

Bacterial isolate FL5 was selected based on its ability to grow abundantly on fluorene amended medium. The isolate was Gram-negative, rod shaped as depicted in SEM (Figure 1), with opaque creamy appearance in agar plate, non-motile, catalase positive and oxidase negative. FL5 is unable to hydrolyze phenylalanine, gelatin or esculin; however, it utilizes citrate, arabinose, fructose, glucose, maltose, mannitol and xylose. Acid production was noted with glucose source. It showed growth between a $\mathrm{pH}$ range of 6-9 and a temperature range of $25-50^{\circ} \mathrm{C}$. Furthermore, the bacterial isolate reduced nitrate to nitrite. The limited diversity of bacterial community in a sample with fluorene was unsurprising due to its extreme toxic environment. Only organisms capable of utilizing fluorene

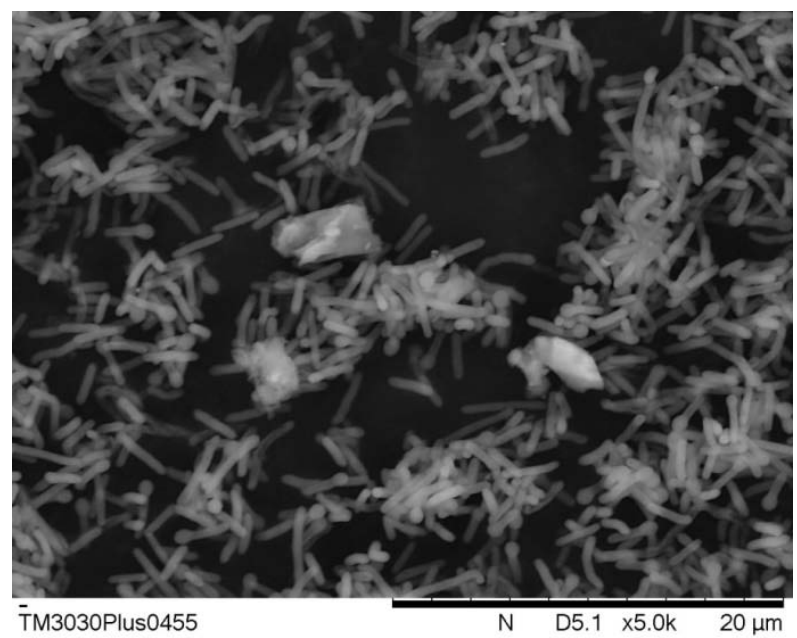

Figure 1. SEM showing rod-shaped bacterial isolate FL5.

can survive. Many phenotypic, biochemical, and physiological properties of this isolate resembled the Citrobacter species, which was further confirmed via 16S rRNA gene analysis.

Nucleotide BLAST and RDP-II analysis showed that isolate FL5 belonged to the phylum Gammaproteobacteria and Enterobacteriaceae family. Phylogenetic analysis revealed it to be of the Citrobacter species (Figure 2). Seven sequences of Citrobacter were included in the dataset. Plesiomonas shigelloides was included as an outgroup taxon for rooting purposes. Isolate FL5 was identified as Citrobacter sp. when compared with the other sequences present in the NCBI database, and was deposited under the accession number KT890283. This was the first report on the extensive characterization of fluorene degrading Citrobacter sp.

\subsection{Biodegradation Studies of Fluorene}

The ability of Citrobacter sp. FL5 to degrade fluorene in cultures was investigated. The isolate was able to grow and utilize fluorene as a sole carbon and energy source. Bacterial growth analysis was done up to 168 hours, and was observed to be growing significantly in media containing $50 \mathrm{mg} \mathrm{L}^{-1}$ of fluorene. The growth of FL5 increased with respect to time (Figure 3). Fluorene was rapidly degraded in the medium, concomitant with bacterial growth. The data showed that Citrobacter sp. FL5 was able to remove high amounts of fluorene within $168 \mathrm{hrs}$.

It has often been observed that $\mathrm{pH}$ and temperature play an important role in biodegradation processes $^{[14,15]}$. The effect of $\mathrm{pH}$ on fluorene biodegradation was depicted in Figure 3 in which the removal of 


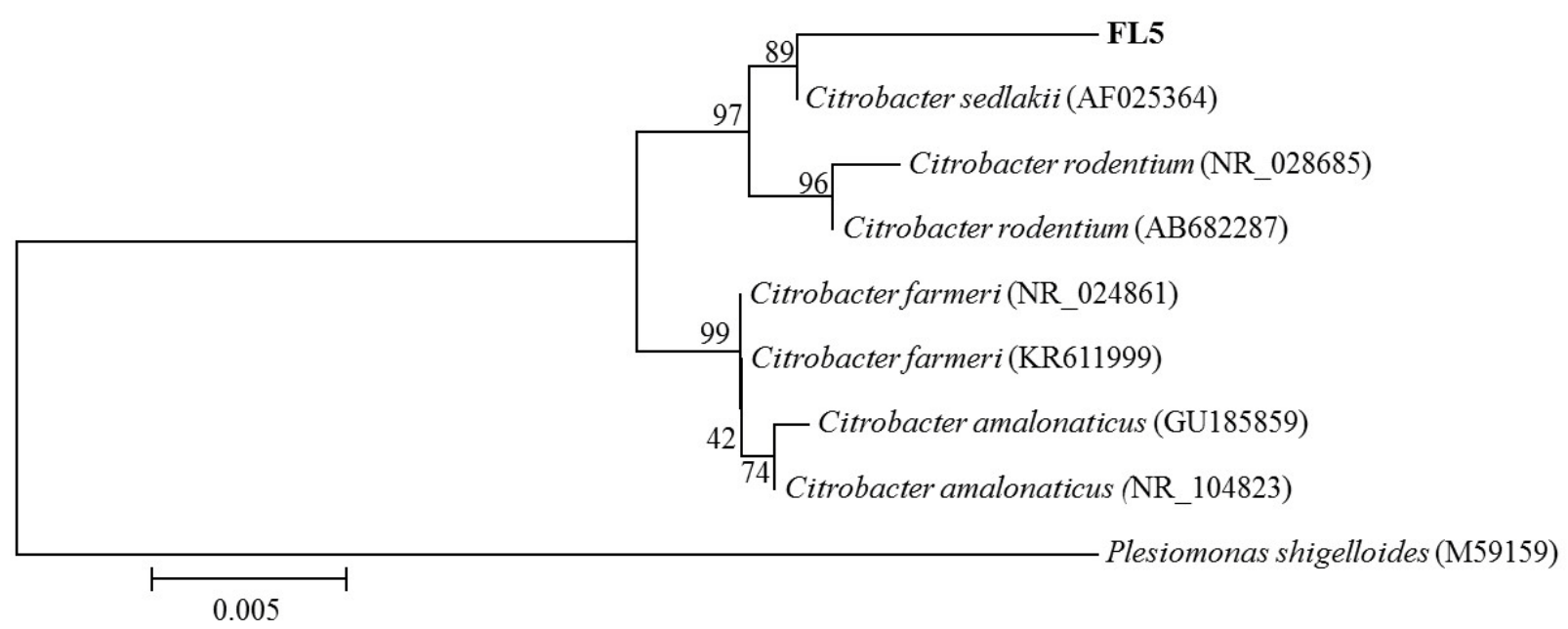

Figure 2. Phylogenetic tree of FL5 generated from Neighbor-Joining (NJ) analysis of 16S rDNA sequences rooted with Plesiomonas shigelloides. Numbers at the branch points indicate bootstrap values (\%) based on NJ analysis of 1000 replicate datasets.
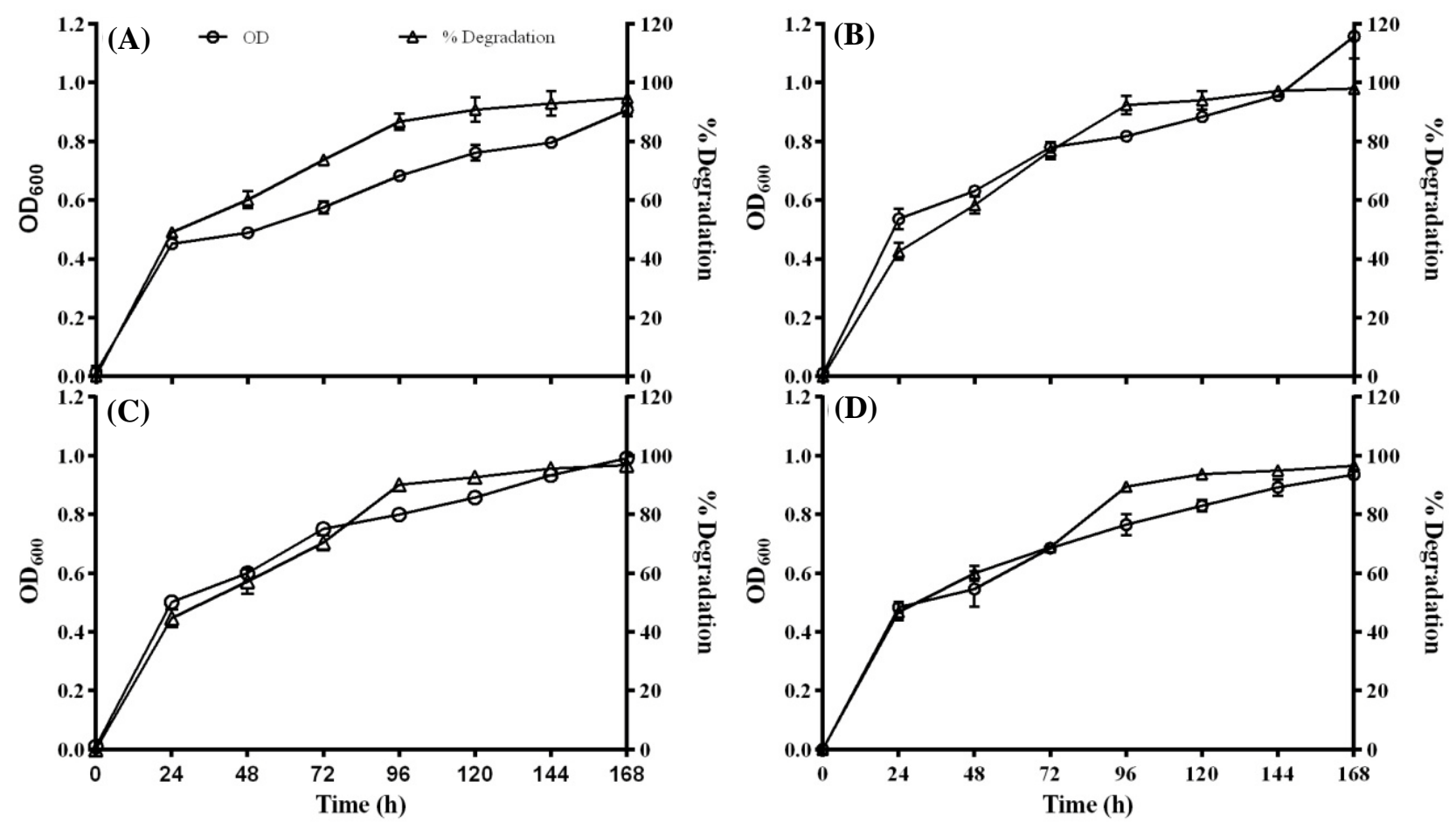

Figure 3. Growth and fluorene degradation by Citrobacter sp. FL5 at (A) pH 6, (B) pH 7, (C) pH 8, and (D) pH 9 at 50 mg L $\mathrm{L}^{-1}$ initial concentration of fluorene. Error bars represent the standard deviation. (OD: Optical Density - absorbance wavelength)

$50 \mathrm{mg} \mathrm{L}^{-1}$ of fluorene with different initial $\mathrm{pH}$ value has been shown. This suggested that the $\mathrm{pH}$ value of minimal media could affect fluorene degradation to a certain extent. The results indicated that Citrobacter sp. FL5 degrades $94.8 \%$ fluorene with the initial $\mathrm{pH}$ value of 6 , relatively lower compared to the other $\mathrm{pH}$ due to slower bacterial growth. At the initial $\mathrm{pH}$ value of 7, Citrobacter sp. FL5 removed 98\% of fluorene. When the initial $\mathrm{pH}$ value was 8 , the isolate removed fluorene by $96.8 \%$. The bacterial isolate showed better growth profile at $\mathrm{pH} 7$ followed by at $\mathrm{pH} 8$ and 9 . Fluorene degradation, $\mathrm{D}(\%)$ was $96.6 \%$ at $\mathrm{pH} 9 . \mathrm{pH}$ is one of the crucial abiotic factors for the survival and activity of microorganisms ${ }^{[16]}$. In this study, neutral to alkaline conditions ( $\mathrm{pH}$ 7.0-9.0) were more favorable for the degradation of fluorene than in acidic conditions (pH 6.0), and optimal degradation was achieved at $\mathrm{pH} 7.0$. 
Citrobacter sp. FL5 was able to degrade significant amounts of fluorene at a wide range of temperatures $\left(25-45^{\circ} \mathrm{C}\right)$. The optimal temperature for fluorene degradation was $30^{\circ} \mathrm{C}$ where $98 \%$ degradation was achieved (Figure 4). At $37^{\circ} \mathrm{C}$, Citrobacter sp. FL5 degraded $90 \%$ fluorene, and $67 \%$ at $45^{\circ} \mathrm{C}$. Optimum temperature enhanced microbial activity. The optimum conditions for maximum fluorene biodegradation were $\mathrm{pH} 7.0$ at $30^{\circ} \mathrm{C}$. The result was consistent with other reports on PAHs biodegradation efficiency. Bacillus fusiformis isolated from wastewater sludge of an oil refinery showed optimal naphthalene degradation at $\mathrm{pH} 7$ and $30^{\circ} \mathrm{C}^{[17] .}$ Furthermore, among the four temperatures studied, 118 microbial isolates (78.6\%) had an optimal temperature of $30^{\circ} \mathrm{C}$ for PAHs degradation, as previously reported ${ }^{[18]}$. Temperature and $\mathrm{pH}$ of the medium affected PAHs degradation by increasing the solubility of the compound ${ }^{[19]}$.

Citrobacter sp. FL5 effectively degraded high concentrations of fluorene although at higher concentrations it may induce poor bacterial growth. Citrobacter sp. FL5 degraded 96\% fluorene at a concentration of $150 \mathrm{mg} \mathrm{L}^{-1}$, while $97.5 \%$ of fluorene was degraded at a concentration of $100 \mathrm{mg} \mathrm{L}^{-1}$ by the end of $168 \mathrm{hrs}$. The rate of fluorene biodegradation by Citrobacter sp. FL5 was higher than previously reported including Bacillus megaterium ${ }^{[11]}$. Fluorene-degrading Pseuodomonas putida ATCC17514 degraded $100 \mathrm{mg} \mathrm{L}^{-1}$ fluorene; however, it was completed in more than 100 $\mathrm{hrs}^{[20]}$. Pseudomonas sp. JM2 was reported to degrade $40 \%$ fluorene in $96 \mathrm{hrs}$ at an initial concentration of 50 $\mathrm{mg} \mathrm{L}^{-1[21]}$. The isolate in the present study had an uncommonly high tolerance and a rapid degradation rate at a broad $\mathrm{pH}$ and temperature range among many documented fluorene-degrading bacteria. These properties made it potentially useful for the degradation of

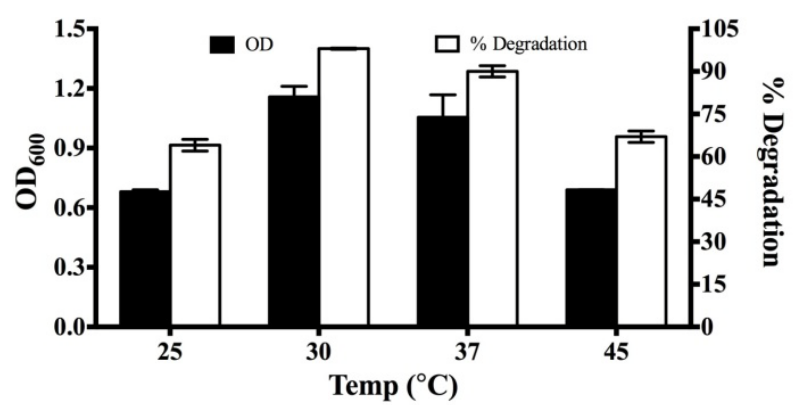

Figure 4. Effect of temperature on the growth and degradation efficiency by Citrobacter sp. FL5 at $50 \mathrm{mg} \mathrm{L}^{-1}$ initial concentration of fluorene. Error bars represent the standard deviation. high concentrations of fluorene in various environments.

\subsection{Metabolites During Fluorene Biodegradation}

In order to determine the intermediate metabolites and pathway during fluorene degradation by Citrobacter sp. FL5, GC-MS analysis was carried out. Unlike direct common metabolites of fluorene biodegradation, such as 9-fluorenol and 9-fluorenone reported in many studies $^{[5,6,10]}$, Citrobacter sp. FL5 produced five different major metabolites, identified as dibenzofuran, 9-fluorenylmethanol, 2,2-diphenylacetic acid, piperonylic acid and catechol (Figure 5). The metabolites showed five main peaks with retention times of 13.035, 21.612, 22.219, 22.794, and 23.384 min (Table 1). As a result, a pathway for fluorene biodegradation by Citrobacter sp. FL5 was proposed (Figure 6). Dibenzofuran is susceptible to angular dioxygenase attack ${ }^{\text {[22] }}$ and its production suggested initial oxidation of fluorene to form its heteroatomic analog which oxidizes to 9-fluorenylmethanol. Upon further ring cleavage and probable involvement of dehydrogenase, catechol was formed as a simple metabolite of fluorene degradation. Further studies are required in order to purify the compound and identify if other metabolites are involved in between the process.

\section{Conclusion}

This work demonstrated the exceptional ability of Citrobacter sp. FL5 in degrading fluorene. The strain was able to significantly degrade fluorene even at higher concentrations in a short time period. In conclusion, due to broad $\mathrm{pH}$ ranges, strong degradation ability, and adaptability to temperature variations, Citrobacter sp. FL5 is a promising candidate bacterium for the bioremediation of fluorene from contaminated environments. Based on our knowledge and review, this was the first study on the biodegradation of fluorene by Citrobacter sp.

\section{Conflict of Interest and Funding}

The authors declared no potential conflict of interest with respect to the research, authorship, and/or publication of this article. This work was supported by the National Water Pollution Control and Management Technology Major Project (No. 2013ZX07310001) and Research Innovation Fund from East China Normal University (No. 78210267). 

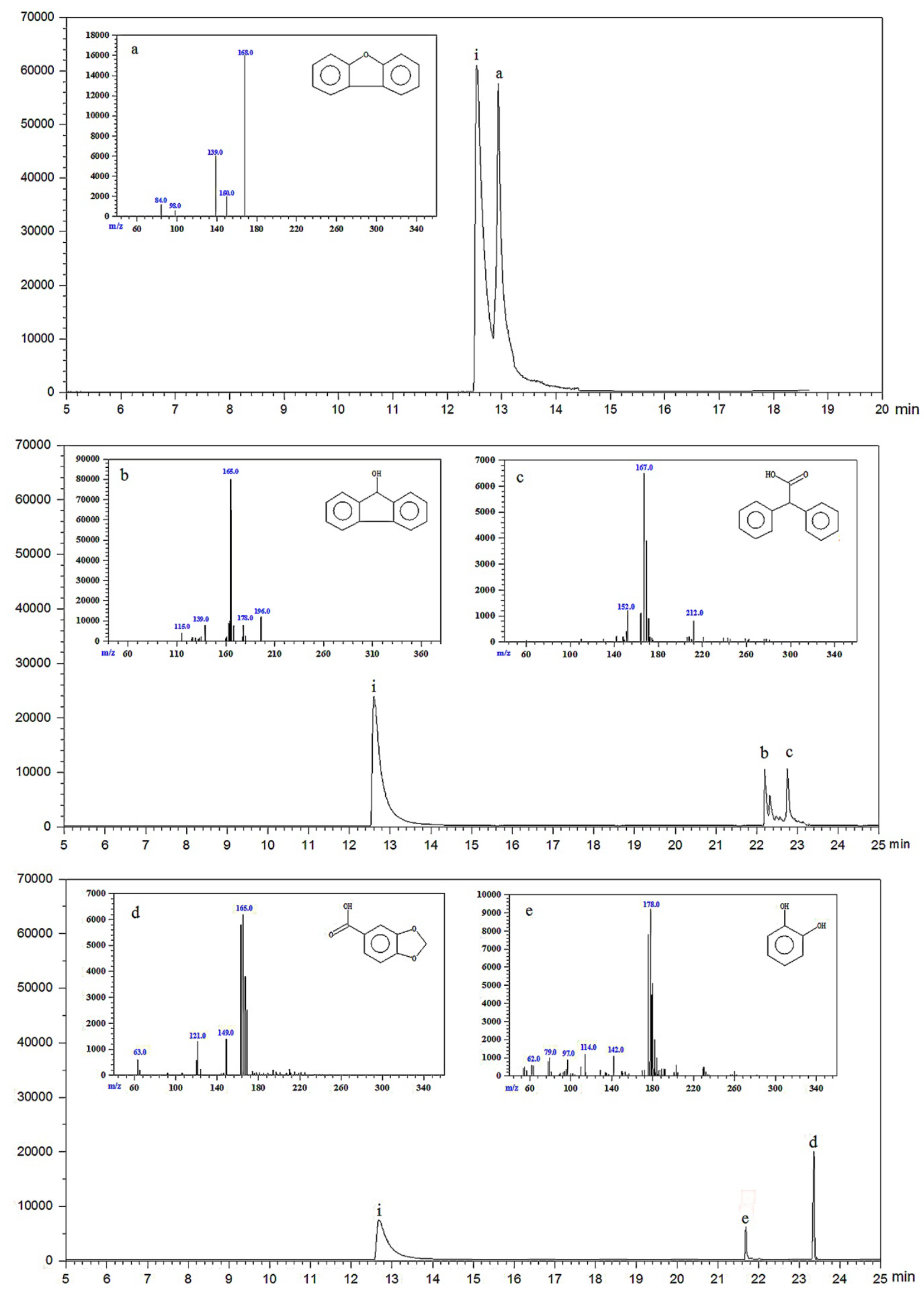

Figure 5. GC chromatogram of metabolites (i) fluorene, (a) dibenzofuran, (b) 9-fluorenylmethanol, (c) 2,2-diphenylacetic acid, (d) piperonylic acid, and (e) benzenediol produced during fluorene degradation by Citrobacter sp. FL5. 
Table 1. GC retention time and electron impact mass spectral properties of metabolites formed during fluorene degradation by Citrobacter sp. FL5

\begin{tabular}{ccll}
\hline Metabolite & Retention time (min) & \multicolumn{1}{c}{$\mathrm{m} / \mathrm{z}$ of fragment (\% relative abundance) } & \multicolumn{1}{c}{ Identification } \\
\hline a & 13.035 & 84(10), 98(5), 139(42), 160(15), 163(88) & Dibenzofuran \\
b & 22.219 & 115(5), 139(9), 165(88), 178(11), 196(13) & 2,2-Diphenylacetic acid \\
c & 22.794 & 152(17), 167(92), 212(14) & Piperonylic acid \\
d & 23.384 & $63(8), 121(20), 149(21), 165(90)$ & Benzenediol \\
e & 21.612 & $62(6), 79(9), 97(8), 114(11), 142(10), 178(93)$ & \\
\hline
\end{tabular}

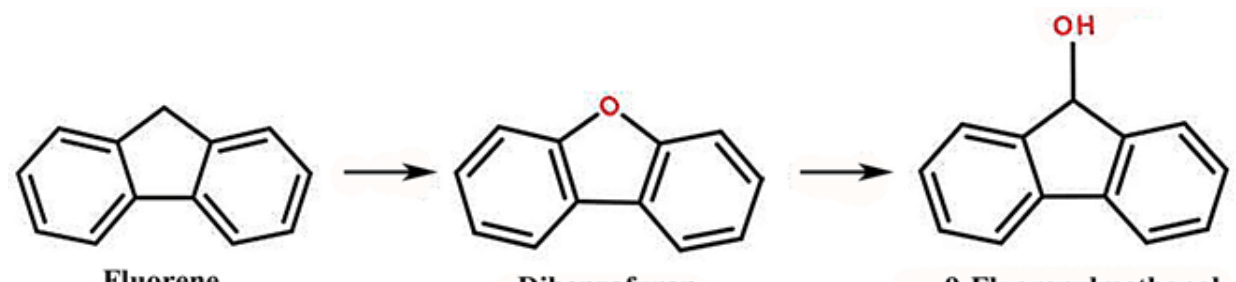

Fluorene
Dibenzofuran<smiles>CCC1(C)Oc2ccc(C(=O)O)cc2O1</smiles>

Piperonylic acid<smiles>Oc1ccccc1O</smiles>

Catechol
9-Fluorenylmethanol<smiles>CCOC(=O)C(c1ccccc1)c1ccccc1</smiles>

2,2-Diphenylacetic acid

Figure 6. Proposed possible pathway of fluorene degradation by Citrobacter sp. FL5.

\section{References}

1. Brenner R C, Magar V S, Ickes J A, et al. 2002, Characterization and FATE of PAH-contaminated sediments at the Wyckoff/Eagle Harbor Superfund Site. Environmental Science and Technology, vol.36: 2605-2613. http://dx.doi.org/10.1021/es011406u.

2. Antizar-Ladislao B, Lopez-Real J and Beck A J, 2006, Bioremediation of polycyclic aromatic hydrocarbons (PAH) in an aged coal-tar-contaminated soil using different in-vessel composting approaches. Journal of Hazardous Materials, vol.137(3): 1583-1588. http://dx.doi.org/10.1016/j.jhazmat.2006.04.056.

3. Grifoll M, Casellas M, Bayona J M, et al. 1992, Isolation and characterization of a fluorene-degrading bacterium: identification of ring oxidation and ring fission products. Applied and Environmental Microbiology, vol.58(9): 2910-2917.

4. Kawasaki S, Jin F and Takada T, 2011, High Dipsersion Power of Cardo-Typed Fluorene Moieties on Carbon Fillers. INTECH Open Access Publisher.

5. Monna L, Omori T and Kodama T, 1993, Microbial degradation of dibenzofuran, fluorene, and dibenzo-pdioxin by Staphylococcus auriculans DBF63. Applied and Environmental Microbiology, vol.59: 285-289.

6. Trenz S P, Engesser K-H, Fischer P, et al. 1994, Degradation of fluorene by Brevibacterium sp. strain DPO 1361: a novel CC bond cleavage mechanism via 1 , 10-dihydro-1, 10-dihydroxyfluoren-9-one. Journal of Bacteriology, vol.176(3): 789-795.

7. Grifoll M, Casellas M, Bayona J, et al. 1992, Isolation and characterization of a fluorene-degrading bacterium: identification of ring oxidation and ring fission products. Applied and Environmental Microbiology, vol.58(9): 
2910-2917.

8. Wattiau P, Bastiaens L, van Herwijnen R, et al. 2001, Fluorene degradation by Sphingomonas sp. LB126 proceeds through protocatechuic acid: a genetic analysis. Research in Microbiology, vol.152(10): 861-872. http://dx.doi.org/10.1016/S0923-2508(01)01269-4.

9. Finkelstein Z, Baskunov B, Golovlev E, et al. 2003, Fluorene transformation by bacteria of the genus Rhodococcus. Mikrobiologiia, vol.72(6): 660-665. http://dx.doi.org/10.1023/B:MICI.0000008365.53111.a4.

10. Casellas M, Grifoll M, Bayona J M, et al. 1997, New metabolites in the degradation of fluorene by Arthrobacter sp. strain F101. Applied and Environmental Microbiology, vol.63(3): 819-826.

11. Hidayati N V, Hilmi E, Haris A, et al. 2011, Fluorene removal by biosurfactants producing Bacillus megaterium. Waste and Biomass Valorization, vol.2: 415-422. http://dx.doi.org/10.1007/s12649-011-9085-3.

12. Krieg N R and Holt J C, (eds) 1984, Bergey's Manual of Systematic Bacteriology. Williams and Wilkins, Baltimore.

13. Achal V and Pan X, 2011, Characterization of urease and carbonic anhydrase producing bacteria and their role in calcite precipitation. Current Microbiology, vol.62(3): 894-902. http://dx.doi.org/10.1007/s00284-010-9801-4.

14. Deeb R and Alvarez-Cohen, 1999, Temperature effects and substrate interactions during the aerobic biotransformation of BTEX mixtures by toluene-enriched consortia and Rhodococcus rhodochrous. Biotechnology and Bioengineering, vol.62(5): 526-536.

15. Ukiwe L N and Egereonu U U, 2012, PH and sulphate mass: intensity factors in investigating sulphatedependent degradation of polycyclic aromatic hydrocarbons. Advances in Applied Science Research, vol.3(2):
1132-1136.

16. Labana S, Singh O, Basu A, et al. 2005, A microcosm study on bioremediation of p-nitrophenol-contaminated soil using Arthrobacter protophormiae RKJ100. Applied Microbiology and Biotechnology, vol.68(3): 417-424. http://dx.doi.org/10.1007/s00253-005-1926-1.

17. Lin C, Gan L and Chen Z-L, 2010, Biodegradation of naphthalene by strain Bacillus fusiformis (BFN). Journal of Hazardous Materials, vol.182(1-3): 771-777. http://dx.doi.org/10.1016/j.jhazmat.2010.06.101.

18. Lee H, Jang Y, Choi Y-S, et al. 2014, Biotechnological procedures to select white rot fungi for the degradation of PAHs. Journal of Microbiological Methods, vol.97: 56-62. http://dx.doi.org/10.1016/j.mimet.2013.12.007.

19. Lau K, Tsang Y and Chiu S, 2003, Use of spent mushroom compost to bioremediate PAH-contaminated samples. Chemosphere, vol.52(9): 1539-1546. http://dx.doi.org/10.1016/S0045-6535(03)00493-4.

20. Rodrigues A C, Wuertz S, Brito A G, et al. 2005, Fluorene and phenanthrene uptake by Pseudomonas putida ATCC 17514: kinetics and physiological aspects. Biotechnology and Bioengineering, vol.90(3): 281-289. http://dx.doi.org/10.1002/bit.20377.

21. Ma J, Xu L and Jia L, 2012, Degradation of polycyclic aromatic hydrocarbons by Pseudomonas sp. JM2 isolated from active sewage sludge of chemical plant. Journal of Environmental Sciences, vol.24(12): 21412148. http://dx.doi.org/10.1016/S1001-0742(11)61064-4.

22. Bressler D C and Fedorak P M, 2000, Bacterial metabolism of fluorene, dibenzofuran, dibenzothiophene, and carbazole. Candian Journal of Microbiology, vol.46(5): 397-409.

http://dx.doi.org/10.1139/cjm-46-5-397. 